\section{Reseña del libro de Dina Beltrán López, De la utopía a la realidad, de la realidad a la utopía. La Universidad de Occidente en Sinaloa (1918-1922) ${ }^{1}$}

María-de-Lourdes Alvarado

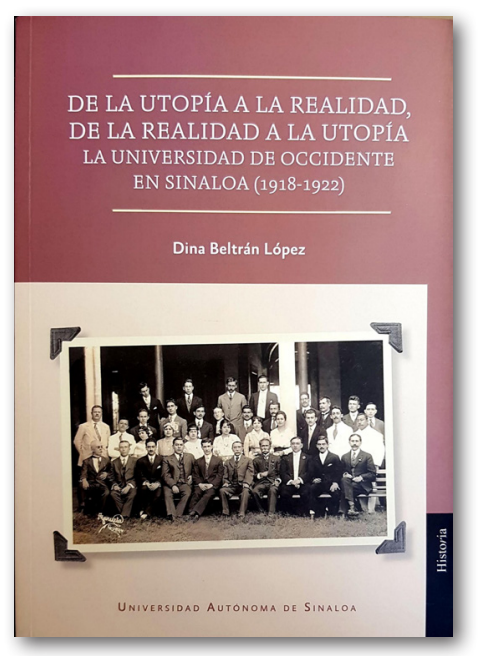

O omo se ha expresado en diversas ocasiones y por no pocos colegas dedicados al estudio histórico de la educación, a través de este rico y extenso campo del conocimiento el investigador no sólo descubre y da a conocer el pasado de los diversos tipos y niveles de instituciones de enseñanza, incluidas las universidades, cuyo conocimiento fue uno de los primeros objetos de estudio de dicha disciplina; también indaga sobre temas muy variados, como son los principales actores de la educación, es decir, alumnos y profesores; currículos, planes de estudio, así como las filosofías, demandas sociales y políticas oficiales que los han inspirado; prácticas docentes, valores educativos y vida cotidiana al interior de las aulas, entre otras múltiples facetas que hoy son abordadas desde este fecundo campo del conocimiento.

Sin embargo, paralelamente a las vertientes propias de la disciplina, el estudioso de la materia se adentra en la problemática política, social, económica y, por supuesto, cultural, de una época y lugar determinado. De este complejo cognoscitivo y de la capacidad y profesionalismo con el que se aborde y delinee, resulta una narración "integral”, profunda, compleja, con múltiples enfoques y aristas que se entrelazan y complementan entre sí para brindar al lector una explicación más completa de las circunstancias en torno al objeto de estudio seleccionado.

María-de-Lourdes Alvarado

alvamaresco@gmail.com Mexicana. Doctora en Historia. Investigadora del Instituto de Investigaciones sobre la Universidad y la Educación (IISUE), Universidad Nacional Autónoma de México (UNAM). Temas de investigación: historia de la educación, educación y género.

${ }^{1}$ Dina Beltrán López, (2018), De la utopía a la realidad, de la realidad a la utopía. La Universidad de Occidente en Sinaloa (19181922), México, Universidad Autónoma de Sinaloa. 
Precisamente es el caso de este libro, De la utopía a la realidad, de la realidad a la utopía. La Universidad de Occidente en Sinaloa (1918-1922), de la pluma de Dina Beltrán López, quien a través de esta interesante investigación se propuso conocer el origen y desempeño de la Universidad de Occidente, consciente de la importancia fundamental que representa vincular el estudio de los procesos históricos de instituciones de educación superior (IES) con los problemas que las aquejan en el presente. Sin duda, la escritora considera que un sistema educativo que ignora su pasado está condenado a reproducir sus errores y frenar su desarrollo, por lo cual será incapaz de cumplir con el cometido social al que está destinado.

Por ello, el presente texto, además de presentarnos un amplio y detallado análisis de los orígenes, contexto sociopolítico, metas, circunstancias, planes de estudio de las diferentes carreras ofrecidas por la institución objeto de su interés, actores académicos principales, relaciones con el Estado, problemas e intereses diversos, aciertos y tropiezos experimentados, entreteje con sumo detalle y conocimiento del tema los vericuetos de la política nacional y estatal durante la etapa revolucionaria, y analiza la forma en que estos sucesos influyeron y condicionaron el destino inmediato de dicha Casa de Estudios, cuya breve existencia se desarrolló entre 1918 y 1922.

Por tanto y para fortuna del lector, el texto que nos ocupa está muy lejos de ser la historia rígida, aislada, lineal de una institución educativa, sino que gracias a un enfoque metodológico novedoso y a la sólida investigación que la sustenta, logra ensanchar las fronteras disciplinares y entrelazar, con gran equilibrio, las diversas facetas e interpretaciones derivadas de la mirada múltiple con que fue abordado.

Es así como la estudiosa de la educación va más allá de una historia institucional, presentándonos, además, una historia cultural de la política sinaloense, analizada desde la perspectiva de su primera Universidad. Interesante por reflejar las graves dificultades económicas y políticas que enfrentó el gobierno en funciones, al momento de la creación de la Universidad de Occidente, como inicialmente se bautizó a la institución, se le asignó un perfil regional, ya que de acuerdo con sus promotores, únicamente si se articulaban los recursos materiales y académicos de varios estados - Sinaloa, Sonora, Nayarit - y el territorio de Baja California, se lograrían superar las limitantes que cada uno de ellos tenía para sostener por sí solos una institución de tal nivel educativo. Sin embargo, como bien señala la autora, esta modalidad, al parecer pionera en la república, no pudo concretarse debido a que, como dice un refrán mexicano, "una cosa es prometer y otra muy distinta es dar", sobre todo cuando se trata de recursos económicos. Así, comenta Beltrán, la naciente Universidad "no recibió más aportaciones que las obtenidas por concepto del subsidio estatal y las provenientes de las cuotas estudiantiles y de los donativos particulares".

Sin descuidar ambos escenarios - nacional y estatal-, este libro analiza cuidadosamente las diversas particularidades y altibajos de la Universidad de Occidente, algunas de cuyas normas y prácticas académicas compara con las del Colegio Rosales, su antecedente natural, y con las propias de la Universidad Nacional de México, fundada por Justo Sierra en la capital de la república, sólo unos años atrás (1910) y, sin duda, otro de sus referentes obligados. Por ejemplo, tras presentarnos el panorama general del estado de la educación en Sinaloa durante el gobierno del general Ramón F. Iturbe, la autora hace hincapié en que al decir de este último dirigente, desde entonces "llegaban hasta el terruño sinaloense los rayos de luz de la Universidad Nacional”, expresión que, por supuesto, refleja la relación que existía entre ambas casas de estudio.

Pero de igual forma que alude a esta importante influencia, señala las diferencias entre una y otra institución, como sucedió con la conformación del Consejo Universitario en la Universidad de Occidente que, a diferencia de lo acontecido en la Universidad Nacional, únicamente se conformó por autoridades 
y profesores. Es decir, el establecimiento sinaloense excluyó la representación del sector estudiantil en este importante órgano de gobierno.

Además de dichas coincidencias y diferencias, el texto en cuestión subraya aquellos aspectos en los que la Universidad de Occidente se adelantó al plano nacional, como fue el carácter regional que se le asignó, idea que según palabras de la autora, inspiró al rector José Vasconcelos, quien tiempo después propuso el establecimiento de cuatro instituciones universitarias en el Proyecto de Ley para la Creación de la Secretaría de Educación Pública. Éstas deberían ser autónomas, aunque sostenidas con fondos federales; gratuitas para los alumnos sin recursos, y ubicarse en diversas zonas estratégicas del país. Asimismo, Beltrán se refiere a los dos ciclos en los que la Universidad de Occidente dividió la curricula del bachillerato - preparatoria primaria y preparatoria secundaria-, decisión que precedió a la medida equivalente adoptada con posterioridad por el gobierno federal .

Así, el texto De la utopía a la realidad, ofrece al lector un análisis integral y comparativo de la educación preparatoria y universitaria sinaloense durante el periodo estudiado, destacando en todo momento, como ya se indicó, las particularidades y aportaciones específicas de la Universidad de Occidente al ámbito educativo nacional, entre las cuales la autora distingue de manera muy especial su carácter autónomo, condición en la que únicamente la antecedió la Universidad Michoacana de San Nicolás de Hidalgo, primera a nivel nacional en ostentar dicha categoría (1917) y secundada en 1923 por la de San Luis Potosí.

De acuerdo con la escritora, precisamente esta última característica representa el punto de ruptura más significativo entre la Universidad y el Colegio Rosales, cuyo funcionamiento durante más de cuatro décadas fue determinado por la Junta Directiva de Estudios, a su vez presidida por el Ejecutivo del Estado. En contraste, la condición autónoma de la
Universidad permeó el discurso y la práctica de profesores y autoridades a lo largo de sus años de vida.

Como bien indica Beltrán López, el tránsito del Colegio Rosales a Universidad de Occidente constituyó una temprana y ambiciosa respuesta del estado de Sinaloa ante los cambios y retos emergentes que imponía el movimiento revolucionario y el establecimiento de un nuevo orden constitucional. Tanto la fundación de esta última institución como su aspiración autonómica sorprenden y muestran el empuje y proyección a futuro de sus fundadores, pues en medio de la confusión general, efecto de la prolongada lucha armada que aquejaba al país, se echó a andar una institución novedosa, orientada al fortalecimiento y modernización del estado, pero cuya presencia en el ámbito educativo y político sinaloense, en particular su carácter autónomo, provocó desconfianza y constantes ataques por parte de ciertos sectores de la población.

Las críticas y descalificaciones en su contra, algunas particularmente álgidas, provenían del grupo encabezado por el general Ángel Flores, partidario de la causa obregonista y acérrimo contrincante político del gobernador Ramón F. Iturbe, quien en contraste con aquél se distinguió por su lealtad a Carranza.

Como era de esperarse, dado el impacto y protagonismo de ambos personajes en los acontecimientos del estado, la autora describe las características de su formación, su trayectoria política, militancia revolucionaria y constantes desencuentros, los que, como suele suceder, acabaron por reflejarse en el ámbito educativo estatal. La confrontación entre uno y otro fue una lucha sin cuartel que cubre el periodo de vida de la Universidad de Occidente. Mientras que el gobernador Iturbe mostró particular interés por el establecimiento y sostenimiento de la Universidad, propuesta que formó parte de su plan de gobierno inicial, Flores, por el contrario, fue un constante defensor del Colegio Rosalino.

Solo por citar un ejemplo de las múltiples críticas dirigidas contra la nueva institución, reproducimos un poema de Eduardo Betancourt, "Fausto", 
publicado en el Demócrata Sinaloense del 18 de septiembre de 1919, el cual muestra la desaprobación y añoranza que en un sector de la población provocó la transformación del antiguo Colegio Rosales en Universidad de Occidente:

No tu poder, joh vanidad! Resiste / La de Humaya, Culiacán hermosa; / Le mataste su joya más preciosa / Al Colegio Rosales muerte diste / No sabes, vanidad, el mal que hiciste; / Te ciega tu altivez y te hace odiosa; / Aquella juventud tan estudiosa, / Por su Rosales clama; jestá muy triste! / Adiós joh buen Colegio! Ya la Historia / Dice: que tu labor fue meritoria, / Que hiciste a la ignorancia muchos males. / Adiós, descansa en paz querido ausente, / Que tu dulce memoria está presente / En esa juventud. jAdiós Rosales!

Otro de los principales obstáculos que la novel institución debió enfrentar y al que con justa razón Beltrán concede especial peso por las graves repercusiones que tuvo en su destino inmediato fue el problema que significó su financiamiento, el cual padeció desde sus orígenes y, en gran medida, contribuyó a su cierre definitivo. A sólo unos días de su inauguración, sostiene la estudiosa del pasado universitario, se observaron los primeros síntomas de dicho problema: de los 50000 pesos inicialmente contemplados en el presupuesto anual de egresos aprobado por el Congreso del Estado, únicamente quedaban 9 000, cifra a todas luces insuficiente para solventar los gastos faltantes. Con el paso del tiempo, la caída de Iturbe y el fortalecimiento político del general Flores, la situación se agravó aún más, al punto que, en abril de 1920, el rector Bernardo José Gastélum Izábal se vio ante la necesidad de proponer diversas alternativas para intentar sortear la dificil situación. En primer término, el funcionario universitario planteó que se enviara a sus casas a los alumnos internos, ya que no había fondos suficientes para cubrir sus gastos; en segundo lugar, hizo un llamado al profesorado para que, como muestra de altruismo y lealtad para con la institución, "sirviera sus clases gratuitamente", solicitud que por otra parte no nos sorprende, pues fue una práctica bastante común a lo largo del historial educativo del país. Como una medida más para atenuar la falta de recursos incrementada por las crecientes pugnas políticas y la disminución de las aportaciones gubernamentales, se decidió aumentar las cuotas impuestas a los alumnos universitarios, práctica que según Beltrán no era nueva, sino que se había puesto en práctica desde la etapa final del Colegio Rosales.

Incluso en 1922, en medio de la renovación del Congreso local y de las cámaras legislativas federales, Gastélum propuso ante el Consejo Universitario suprimir el sueldo del rector y, al menos temporalmente, el puesto de secretario, además de algunas otras medidas desesperadas encaminadas al mismo fin. Si bien éstas no fueron aprobadas por el Consejo, dan cuenta de la gravedad del problema económico por el que atravesaba la Universidad.

En los dos últimos capítulos, la autora profundiza y detalla los obstáculos y diversas circunstancias que confluyeron y determinaron el fin de la primera institución universitaria establecida en Sinaloa y en el noroeste mexicano. Describe la cerrada madeja de intereses federales y estatales que, hacia los inicios de la década de los veinte del siglo pasado, se entretejieron y determinaron el destino de la Universidad, dice Beltrán: "La participación de los universitarios en la contienda electoral [de julio de 1922], agregó un elemento de tensión más a la ya de por sí ríspida relación entre el gobierno estatal y el centro de estudios, pues un sector de la élite gobernante sintió como una grave amenaza que los rosalinos quisieran invadir las que consideraban sus parcelas de poder".

Asimismo, describe con detenimiento el forcejeo de intereses que se reactivaron con motivo del inminente cierre de la institución, aunque éste no se resolvió de inmediato, sino que para consumarse definitivamente requirió de varios meses y no 
pocos intentos. Lo cierto es que en la medida que se acrecentaba la falta de recursos, las críticas se recrudecían, al punto que hubo quien sentenció que la Universidad pasaría a la historia como una "cosa inservible", pues había sido incapaz de rendir los frutos esperados. Tampoco faltaron algunos resentidos que dirigieron sus diatribas contra los universitarios a quienes veían como una casta de supuestos intelectuales, palabras que nos recuerdan las críticas expresadas hacia los inicios del siglo XX por Agustín Aragón y Horacio Barreda, contra la pedantocracia que, de acuerdo con su punto de vista, constituía a la Universidad Nacional.

Finalmente, pese a algunos intentos fallidos por impedir la clausura de la institución, entre los que figura la presión ejercida ante el presidente Álvaro Obregón por parte de las diputaciones federal y estatal, todo fue inútil. Según palabras de Beltrán, durante el último año de gobierno del político sonorense, el 18 de octubre de 1924 para ser más exactos, el Consejo Universitario "dobló las manos y acordó autorizar al rector para que depositara en la Tesorería General del Estado todos los fondos que tenía en su poder". No obstante, debido a la confusión reinante y a los esfuerzos realizados por quienes luchaban contra la consumación de dicha medida, ésta se llevó a cabo en marzo de 1925. Es decir, en medio de las pugnas partidistas, la incapacidad de las autoridades para solventar los gastos institucionales indispensables y la constante embestida de sus enemigos, el Consejo optó por "quemar las naves" de la primera Universidad establecida en tierras de occidente, con lo cual llegó a su fin el ciclo de vida de una institución que llenó un importante capítulo del pasado educativo de la entidad y del noroeste de la república. Como bien indica Dina Beltrán, pese a sus indudables cualidades académicas y a su innovador programa de estudios, la Universidad de Occidente no logró arraigarse en la sociedad que le dio vida porque no contó con las condiciones económicas, sociales, pero sobre todo políticas, que lo permitieran.
Los irreconciliables enfrentamientos entre la clase política revolucionaria, tanto a nivel nacional como local, así como la crisis económica que siempre la acompañó, determinaron su fin y el resurgimiento temporal del Colegio Civil Rosales, cuyo funcionamiento abarcaría hasta 1937 durante el gobierno cardenista, cuando daría paso a una nueva etapa en la trayectoria universitaria del estado, convirtiéndose en la Universidad Socialista del Noroeste.

Aspecto fundamental del texto que nos ocupa es el rigor académico que respalda toda la investigación y del que da cuenta la variedad de fuentes historiográficas de las que hace gala, conformada por la rica y actualizada bibliografía presente en el aparato crítico que apuntala todo el discurso, además de la atinada selección hemerográfica que enriquece y complementa su contenido con materiales novedosos y esclarecedores de la problemática estudiada.

Por lo que toca al andamiaje de la investigación, revela una sistemática y meticulosa revisión de los repositorios documentales pertinentes para la temática abordada, como son el Archivo Histórico de la Universidad Autónoma de Sinaloa, el Archivo del Congreso y el General de Notarías del mismo estado, el Archivo Histórico Municipal de Culiacán, el Archivo Histórico y el del Consejo Universitario, de la Universidad Nacional Autónoma de México, el Archivo General de la Nación, el Archivo de la Cámara de Diputados del Congreso de los Estados Unidos Mexicanos y el Archivo Histórico Diplomático Genaro Estrada, de la Secretaría de Relaciones Exteriores.

La información generada por dichas fuentes, integrada en un discurso bien estructurado y expuesto con gran claridad, cualidades que aunque parezca increíble no siempre caracterizan a las publicaciones académicas, hacen de este volumen una obra de consulta obligada, no sólo para los historiadores de la educación, sino también para un público más amplio, no especializado en la materia, pero igualmente interesado en la historia de la entidad y en el pasado cultural y político de la región. 
Es también gracias a este rico y novedoso cuerpo informativo que el libro De la utopía a la realidad, de la realidad a la utopía, ofrece al lector 38 tablas con información variada y novedosa, la cual complementa o en su caso enriquece los datos en él consignados. Sólo a manera de ejemplo citamos dos de ellas, la número 21 que da cuenta de la población escolar en la Universidad de Occidente, atendiendo al sexo de las y los alumnos, entre 1918 y 1922, y la 33, en la cual se precisa el monto de las cuotas estudiantiles de la institución, de acuerdo con el presupuesto de 1920.

De igual importancia son también los ocho anexos que contienen documentos de particular valor para la temática investigada, como son el "Decreto número 47 que presenta la Ley que organiza la Universidad de Occidente y le concede su autonomía" o el "Plan de estudios especializado de la Preparatoria del Colegio Rosales (1895, para las carreras de Médico, Farmacéutico, Veterinario y Abogado)". Es claro que tanto las tablas como los anexos son instrumentos de gran utilidad para los lectores, ya sea porque coadyuvan a una mayor comprensión del texto o porque aportan elementos para que otros estudiosos desarrollen nuevas interpretaciones o investigaciones sobre la materia.

Este libro cumple cabalmente con los objetivos que se propuso la autora al dar a conocer las características y vericuetos por los que transitó esta institución durante sus escasos cuatro años de vida. Gracias a él, se hace justicia a un tema del que, pese a su interés e importancia en tanto antecedente remoto de la Universidad Autónoma de Sinaloa, hasta ahora, muy poco se sabía. Consideramos que tanto por su rico contenido como por la información adicional que pone a disposición de las y los lectores, representa una importante aportación para la historiografía de la educación sobre la materia, por lo que celebramos su publicación y por supuesto, invitamos a su lectura.

\section{Cómo citar este artículo:}

Alvarado, María-de-Lourdes (2020), “Reseña del libro de Dina Beltrán López, De la utopía a la realidad, de la realidad a la utopía. La Universidad de Occidente en Sinaloa (1918-1922)”, Revista Iberoamericana de Educación Superior (RIES), vol. XI, núm. 30, pp. 220-225, https://doi.org/10.22201/iisue.20072872e.2020.30.597 [Consulta: fecha de última consulta]. 